\title{
Early increases in ischaemic heart disease mortality dissociated from and later changes associated with respiratory mortality after cold weather in south east England
}

\author{
Gavin C Donaldson, William R Keatinge
}

\begin{abstract}
Study objective-To identify the time courses and magnitude of ischaemic heart (IHD), respiratory (RES), and all cause mortality associated with common 20-30 day patterns of cold weather in order to assess links between cold exposure and mortality.

Design-Daily temperatures and daily mortality on successive days before and after a reference day were regressed on the temperature of the reference day using high pass filtered data in which changes with a cycle length $<80$ days were unaffected $(<2 \%)$, but slower cyclical changes and trends were partly or completely suppressed. This provided the short term patterns of both temperature and mortality associated with a one day displacement of temperature. The results were compared with simple regressions of unfiltered mortality on temperature at successive delays.
\end{abstract}

Study population and setting-Population of south east England, including London, over 50 years of age from 1976-92.

Main results-Colder than average days in the linear range 15 to $0^{\circ} \mathrm{C}$ were associated with a "run up" of cold weather for 10-15 days beforehand and a "run down" for 10-15 days afterwards. The increases in deaths were maximal at 3 days after the peak in cold for IHD, at 12 days for RES, and at 3 days for all cause mortality. The increases lasted approximately 40 days after the peak in cold. RES deaths were significantly delayed compared with IHD deaths. Excess deaths per million associated with these short term temperature displacements were 7.3 for IHD, 5.8 for RES, and 24.7 for all cause, per one day fall of $1^{\circ} \mathrm{C}$. These were greater by $52 \%$ for IHD, $17 \%$ for RES, and $37 \%$ for all cause mortality than the overall increases in daily mortality per ${ }^{\circ} \mathrm{C}$ fall, at optimal delays, indicated by regressions using unfiltered data. Similar analyses of data at 0 to $-6.7^{\circ} \mathrm{C}$ showed an immediate rise in IHD mortality after cold, followed by a fall in both IHD and RES mortality rates which peaked 17 and 20 days respectively after a peak in cold.

Conclusion-Twenty to 30 day patterns of cold weather below $15^{\circ} \mathrm{C}$ were followed:(1) rapidly by IHD deaths, consistent with known thrombogenic and reflex consequences of personal cold exposure; and (2) by delayed increases in RES and associated IHD deaths in the range 0 to $15^{\circ} \mathrm{C}$, which were reversed for a few degrees below $0^{\circ} \mathrm{C}$, and were probably multifactorial in cause. These patterns provide evidence that personal exposure to cold has a large role in the excess mortality of winter.

\section{(F Epidemiol Community Health 1997;51:643-648)}

Mortality from ischaemic heart disease (IHD) increases greatly in winter. ${ }^{1}$ Cold exposure causes increases not only in arterial pressure but in the red cell count, platelet count, blood viscosity, and plasma fibrinogen and cholesterol $^{2}{ }^{3}$ which could cause rapid IHD deaths from coronary thrombosis after cold. Further IHD deaths can be expected secondary to respiratory (RES) disease, since respiratory disease increases in cold weather, ${ }^{4}$ and influenza ${ }^{5}$ and other respiratory ${ }^{7}$ infections are known to be accompanied by increased IHD mortality. Possible causes of IHD deaths after respiratory infection include raised plasma fibrinogen associated with acute phase reaction, ${ }^{8}$ and reduction of fibrinolysis by endotoxin ${ }^{9}$ during secondary infection by $\mathrm{Hae}$ mophilus bacilli. The sizes of increases in mortality with cold weather among populations in western Europe correlate with their levels of protection against cold. ${ }^{10}$ The detailed timing of these increases in relation to cold weather is important in assessing the nature of the link between them.

The main objective of this study was to try to identify separate timings for direct effects of short term temperature changes on IHD mortality and for indirect effects on IHD mortality secondary to respiratory disease. Previous assessments of the timing of IHD and RES mortality related to cold have been based either on multiple regression analysis, relating mortality on a reference day to temperatures on successive days before and after it, or on single regression, relating a change in mortality over a defined period to a change in temperature over the same or a different period. ${ }^{1411}$ Both approaches have suggested that after cold weather IHD mortality rises before RES mortality. However, multicollinearity, random variance, and probably variability in effects of a given day's temperature when preceding temperatures differ make day to day results of 


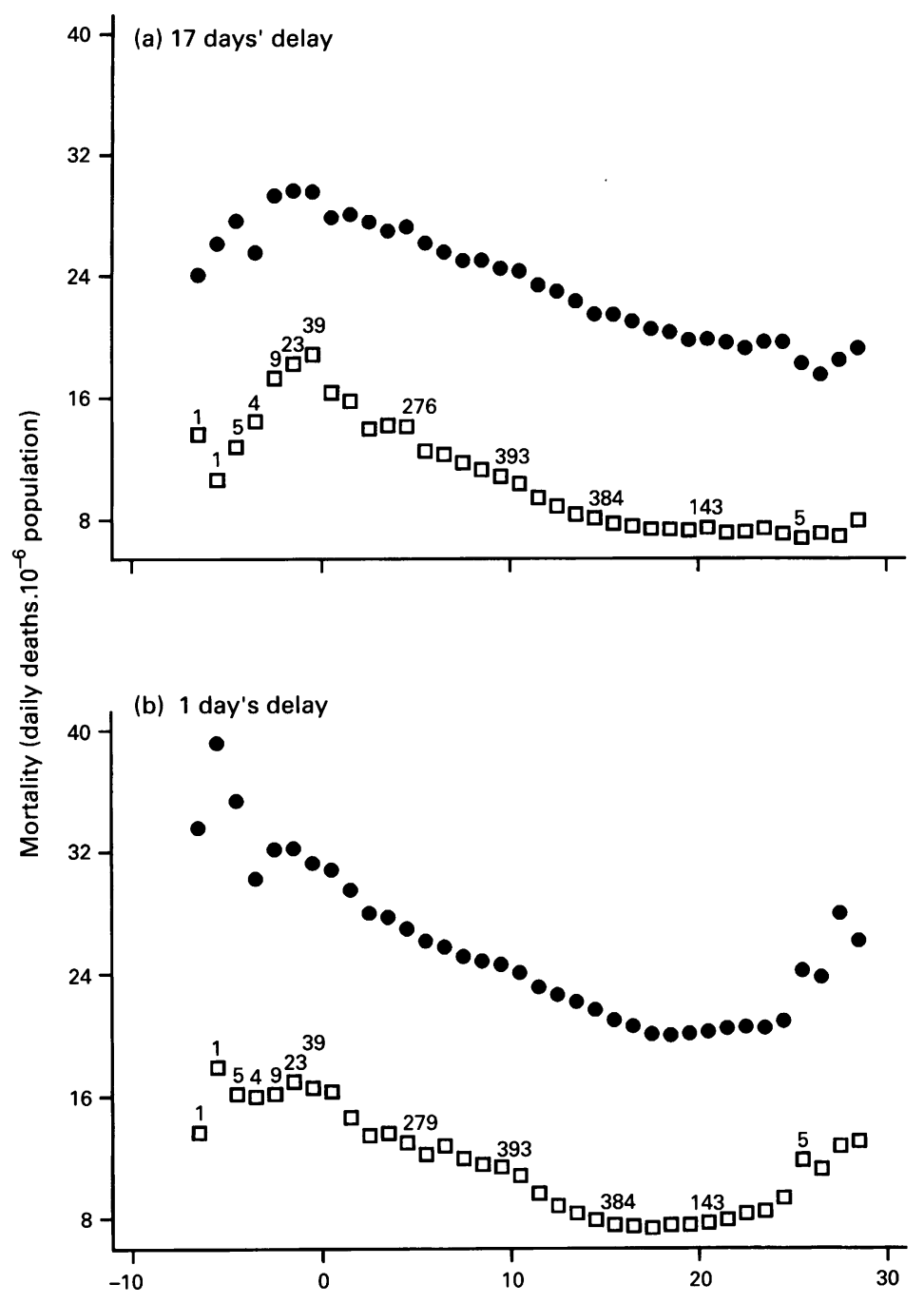

Figure 1 Relation of mortality rates to mean daily temperature at (b) 1 day's delay and (a) 17 days'delay. Ischaemic heart disease is represented by closed circles and respiratory disease by open squares. Numbers above some of the respiratory mortality rates give the number of days at that temperature.

multiple regression analysis unstable and generally non-significant. Analysis based on a change in temperature ignores effects of the large opposite change in temperature which on average precedes such a change. ${ }^{12}$ The present analysis was designed to identify by single regression analysis both the pattern of daily temperatures and the day by day pattern of cause specific mortality associated with a colder than average day in the usual one to two month weather systems. High pass filtering was used to suppress slow cyclical changes and trends. The results were compared with overall relations of mortalities to temperature, which include seasonal and longer changes, obtained by direct regressions of unfiltered mortalities on temperature at successive delays. The analysis used daily data from south east England over 17 years from 1976 and therefore provided large numbers of deaths from a compact region.

\section{Methods}

DATA AND REGRESSIONS

Daily deaths of men and women aged 50 years and over from 1976-92 in Greater London, Hertfordshire, Essex, Kent, East and West Sus-
KEY POINTS

- Exposure to cold is an important cause of excess winter mortality.

- Measures to improve personal protection against cold have an important role in reducing the approximately 50000 excess winter deaths in Britain.

sex, Hampshire, Surrey, Berkshire, Oxfordshire, Buckinghamshire, and Bedfordshire, were extracted in relation to primary cause. Ischaemic heart disease (IHD)was classified as ICD 410.0-414.9, respiratory disease (RES) as 460.0-519.9, and all cause mortality as 0-999.9. Similar analysis for cerebrovascular deaths (ICD 430.0-438.9) gave results which were generally intermediate between IHD and RES and are not reported in detail here. Consistency was maintained between the 8th and 9th ICD series by excluding from the 8 th series ICD 412.9, which was the code for cardiovascular arteriosclerosis and degeneration before 1979 .

Daily estimates of population obtained by linear regression of mid-year population estimates (OPCS, Series DH1, table 2) against date were used to calculate daily mortality as deaths per $10^{6}$ population. The population aged over 50 in the region was $5287 \times 10^{3}$ in 1976 and $5410 \times 10^{3}$ in 1992 . Mortality rates before 1984 were adjusted for changes in coding instructions that year. Ordinary linear analysis was used for all regressions; mean deaths per day were 125 (IHD), 64 (RES), and 479 (ALL). Air pollution was not included in the analysis. ${ }^{13}$ Mean daily temperatures were obtained from three hourly measurements at the Weather Centre, London. For graphs, mortality data was "binned" at $1^{\circ} \mathrm{C}$ intervals.

TIME SERIES ANALYSIS ON FILTERED DATA

For analysis designed to show short term temperature and mortality displacements, mean daily temperatures and mortality data for each cause were digitally filtered using a DolphChebyshev $2.1 \mathrm{~Hz}$ high-pass filter, ${ }^{14}$ and linear trend was removed. ${ }^{15}$ This suppressed $69 \%$ or more of annual or slower changes while having no effect $(<2 \%)$ on changes with cycle lengths of $<80$ days. The procedure discards the initial and final 256 days of the 17 years of data and centres the remainder on zero. With the filtered data, the mean daily temperature each day (day 0 ) that fell in a defined range (unfiltered) of either 0 to $15^{\circ} \mathrm{C}$, or $<0^{\circ} \mathrm{C}$ was used as the independent variable. Coefficients of regression on this were calculated first for temperature and then for each cause specific mortality on successive days before and after the reference day (day 0). Cochrane-Orcutt adjustment ${ }^{16}$ for serial correlation of error terms was not applied to the calculations we report, since all factors affecting temperature-mortality relations, serially correlated or not, were being studied. However, secondary calculations showed that al regression coefficients significantly $(p<0.05)$ different from zero were also significantly different after Cochrane-Orcutt adjustment. 


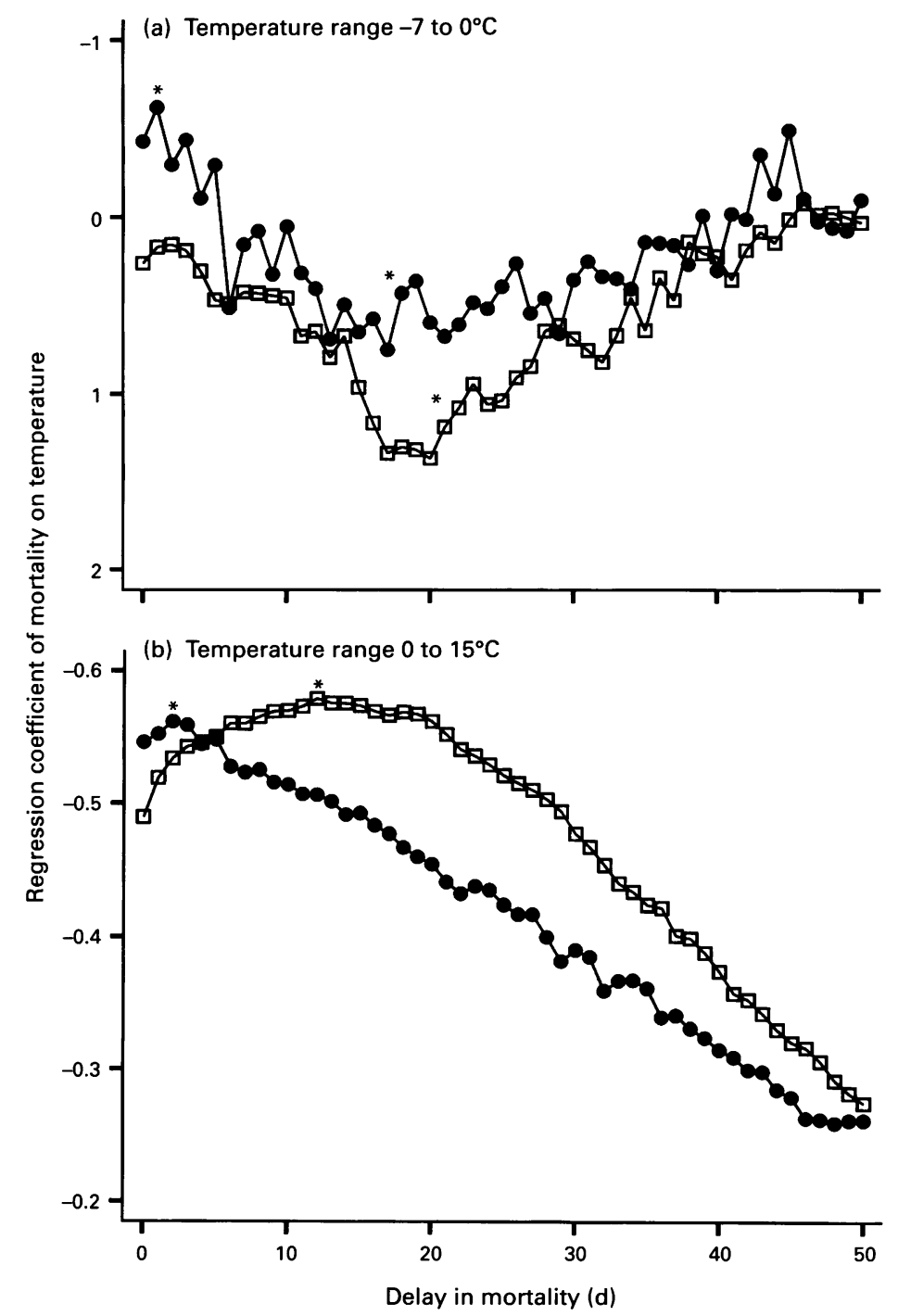

Figure 2 Regression coefficients for mortality rates $\left(10^{-6}\right.$. day $\left.y^{-1}\right)$ on temperature $\left({ }^{\circ} \mathrm{C}\right)$ at successive daily delays (b) In the temperature range 15 to $0^{\circ} \mathrm{C}$. ${ }^{*}$ At these peak displacements, values differ from zero, $p<0.001$. (a) In the temperature range 0 to $-6.7^{\circ} \mathrm{C}$. ${ }^{*}$ At these peak displacements, values differ from zero. $p=0.016$ for ischaemic heart disease (closed circles) at 1 day, $p=0.009$ for ischaemic heart disease at 17 day; $p=0.003$ for respiratory disease (open squares) at 20 days.

Average delay of the daily mortality disturbance was obtained for each cause of death as:

$$
\sum \mathrm{D}_{\mathrm{i}} \mathrm{M}_{\mathrm{i}} / \sum \mathrm{M}_{\mathrm{i}}=-15, \ldots,+40 \text { days. }
$$

where $M$ is the coefficient of regression of daily mortality (filtered) from a given cause of death on daily fall in temperature (filtered); $D$ is day number $i$; is the number of days before or after day 0 ; baseline for $M$ was mean value on days -30 to -16 (see fig 3 ). For statistical comparisons, these delays for each cause of death were calculated for each of the 15 full years for which filtered data were available, and the annual delays for different causes of death were compared with each other by the Wilcoxon matched pairs rank test.

Total mortality from a given cause per $^{\circ} \mathrm{C}$.day fall in temperature was obtained as:

$$
\sum M_{i} / \Sigma T_{i}
$$

where $j=-15, \ldots,+15$ days. Baseline for $T$ was the mean value on days -30 to -16 (see fig 3 ).

OTHER STATISTICAL TERMS

$\mathrm{p}<0.05$ was considered significant.

\section{Results}

SIMPLE MORTALITY-TEMPERATURE RELATIONS

Below $18^{\circ} \mathrm{C}$, IHD, cerebrovascular disease, RES, and all cause mortality rates at any delay up to 50 days increased as temperature decreased to $0^{\circ} \mathrm{C}$ (examples for IHD and RES are given in fig 1). The increases were closely linear below $15^{\circ} \mathrm{C}$, which was accordingly used as the upper limit for analysis. The increase over the range 15 to $0^{\circ} \mathrm{C}$ was steepest (fig 2) at 2 days' delay on temperature for IHD, 12 days' for RES, and at 3 days' for all cause mortality. The increase in cerebrovascular deaths, not described in detail, was steepest at 5 days' delay. Regression coefficients at these delays in daily deaths. $10^{-6} .{ }^{\circ} \mathrm{C}^{-1}$, were -0.56 for IHD, -0.58 for RES, and -2.09 for all cause mortality, and are shown in figure 2(b) for IHD and RES. All were significant $-\mathrm{p}<0.001$.

Below $0^{\circ} \mathrm{C}$, to the lowest recorded temperature of $-6.7^{\circ} \mathrm{C}$, IHD mortality at short delays of 1 to 4 days continued to rise with the fall in temperature (figl(b)); the rise was steepest (fig 2 (a)) at 1 day's delay in this range, with a regression coefficient of -0.63 daily deaths. $10^{-6} .{ }^{\circ} \mathrm{C}^{-1}(\mathrm{p}=0.016)$. At longer delays after a fall in temperature, IHD mortality fell. This was steepest at 17 days delay with a positive regression coefficient of 0.75 deaths.day ${ }^{-1} .10^{-6} .{ }^{\circ} \mathrm{C}^{-1}$ $(\mathrm{p}=0.009$ ) (figs 1(a), 2(a)). RES mortality showed little relation to temperature at delays up to a few days but at longer delays fell with fall in temperature, most steeply at 20 days' delay when the regression coefficient was 1.37 daily deaths. $10^{-6} .{ }^{\circ} \mathrm{C}^{-1}(\mathrm{p}=0.003)$. All cause mortality (not shown in fig 2) in the temperature range also showed little relation to temperature at delays up to 5 days but fell with fall in temperature at longer delays; most steeply at 20 days delay, when the regression coefficient was 3.64 daily deaths. $10^{-6} .{ }^{\circ} \mathrm{C}^{-1}(\mathrm{p}=0.001)$.

TIME SERIES MORTALITY ANALYSES AFTER SHORT TERM TEMPERATURE DISTURBANCES, $15-0^{\circ} \mathrm{C}$ Analysis using high pass filtered data in the range 15 to $0^{\circ} \mathrm{C}$ showed a run up of 10 to 15 increasingly cold days before a colder than average day, followed by 10 to 15 decreasingly cold days (fig 3). Mortality from IHD started to increase almost simultaneously with the fall in temperature but peaked ( $p<0.001) 3$ days after the peak cold and remained high for 30-40 days after peak cold-15-25 days after the temperature had returned to baseline. RES mortality was more delayed. It showed a clear increase only after peak cold, rising slowly to a maximum $(p<0.001) 12$ days after this peak and continuing for approximately 40 days after peak cold- 25 days after temperature returned to baseline (fig 3). Cerebrovascular deaths, which are not described in detail, peaked 4 days after peak cold. All cause deaths peaked $(p<0.001) 3$ days after peak cold, and returned to baseline approximately 40 days after peak cold. Mean delays of mortality on temperature were 8.3 days for IHD, 19.8 days for RES, and 13.8 days for all causes mortality. For IHD and RES these delays differed; $\mathrm{p}=0.031$.

The total increases in mortality and total ${ }^{\circ}$ C.days fall in temperature shown in fig 3, 

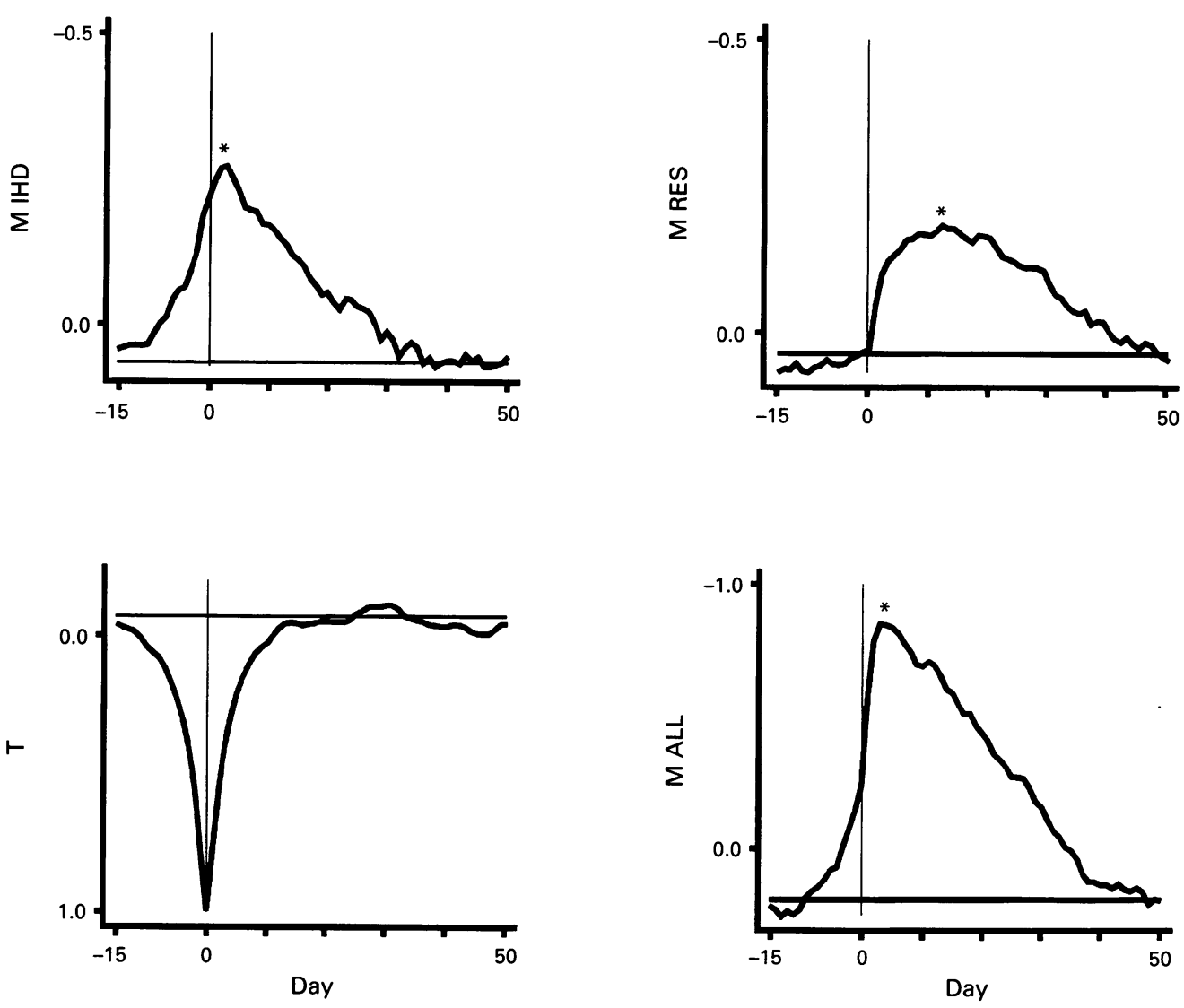

Figure 3 Time series analysis showing the time courses of mean daily temperature $\left(T ;{ }^{\circ} \mathrm{C} .{ }^{\circ} \mathrm{C}^{\prime}\right)$ and mortality rates (M; $10^{\circ} .{ }^{\circ} \mathrm{C}^{1}$ ), associated with a cold day (day 0 ) in the temperature range 15 to $0^{\circ} \mathrm{C}$. Values are regression coefficients of temperature or mortality on temperature on days before and after day 0. Horizontal lines are means of values at -30 to -16 days. IHD=ischaemic heart disease. RES =respiratory disease, and ALL= all cause mortality. ${ }^{*}$ At these peak displacements values differ from zero, $p<.001$.
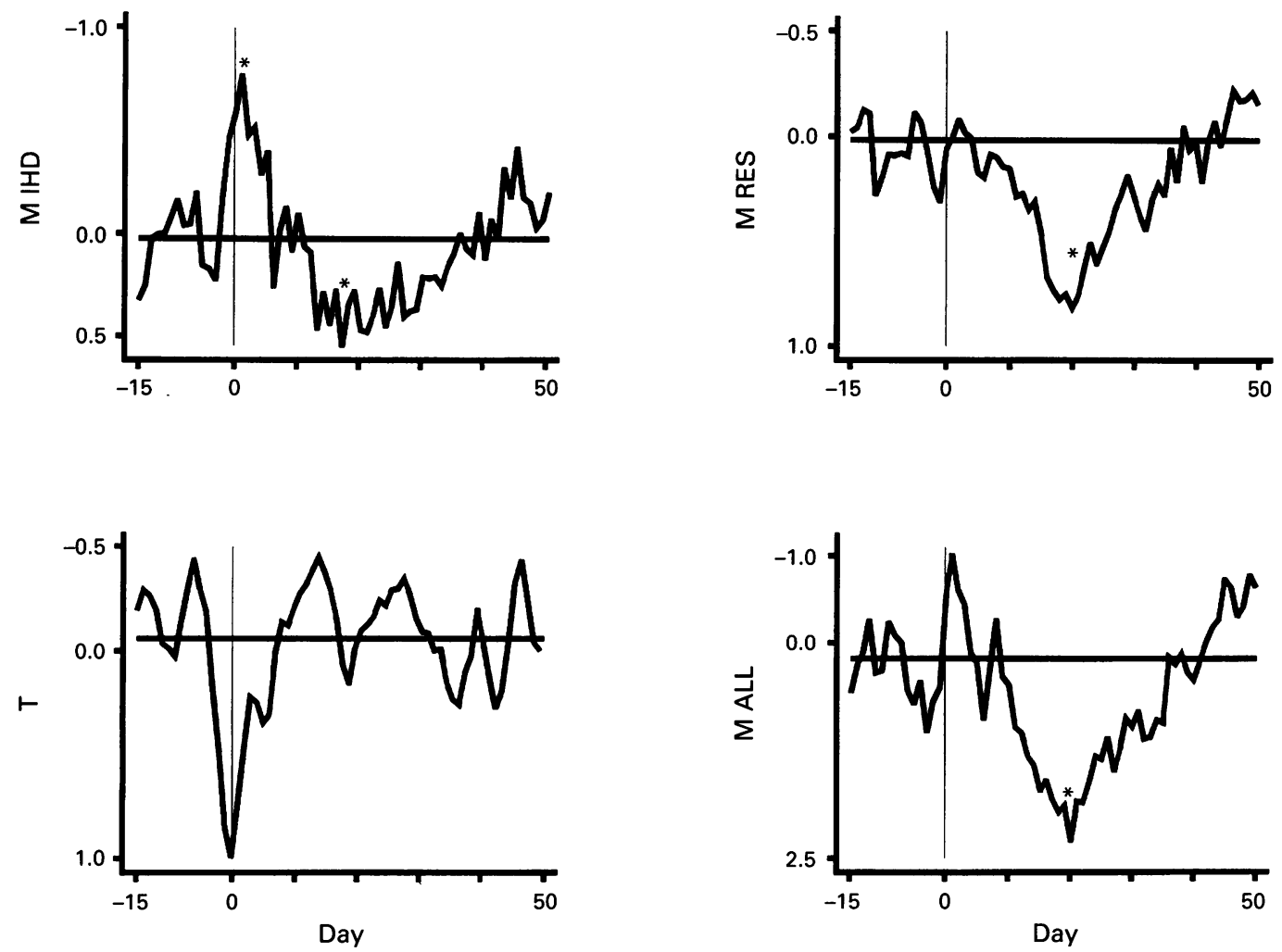

Figure 4 Time series analysis showing time courses of mean daily temperature $\left(T ;{ }^{\circ} \mathrm{C} .{ }^{\circ} \mathrm{C}^{-1}\right)$ and mortality $\left(\mathrm{M} ; 10^{-6} .{ }^{\circ} \mathrm{C}^{\prime}\right)$, associated with a cold day (day 0$)$ in the range 0 to $-6.7^{\circ} \mathrm{C}$. Values are regression coefficients of temperature or mortality on days before and after day 0 . Horizontal lines are means of values at -30 to -16 days. IHD $=i$ schaemic heart disease, $R E S=$ respiratory disease, and $A L L=$ all causes mortality. ${ }^{*}$ At peak positive and negative displacements, values differ from zero, $p<0.001$ IHD at 1 day; $p=0.012$ IHD at 17 days; $p<0.001$ RES at 20 days; $p<0.001$ ALL at 20 days. 
per ${ }^{\circ} \mathrm{C}$ decline in temperature on the reference day (day 0) were 7.26 deaths. $10^{-6}$ for IHD; 5.81 deaths. $10^{-6}$ for RES; 24.68 deaths. $10^{-6}$ for all causes, and $8.59^{\circ} \mathrm{C}$. days fall in temperature. Temperature displacement of $1^{\circ} \mathrm{C}$ for a day was therefore associated with an excess (per $10^{6}$ ) of 0.85 for IHD, 0.68 for RES, and 2.87 for all cause deaths. These increases with short term temperature displacement are greater than the overall seasonal increases in daily deaths. $10^{-6} .{ }^{\circ} \mathrm{C}^{-1}$ fall in temperature, indicated by simple overall regression coefficients with unfiltered data at optimal delays (fig 2), by $52 \%$ for IHD, $17 \%$ for RES, and $37 \%$ for all cause mortality.

\section{TIME SERIES MORTALITY AFTER TEMPERATURE}

DISTURBANCES AT 0 TO $-6.7^{\circ} \mathrm{C}$

Analysis of similar data from the only 79 days colder than $0^{\circ} \mathrm{C}$ (fig 4) showed that a cold spell in the 0 to $-6.7^{\circ} \mathrm{C}$ range was accompanied by rapid increase in IHD mortality, maximal at 1 day after peak cold $(\mathrm{p}<0.001)$, followed after 5 days by a fall maximal at 17 days $(p=0.012)$. RES mortality showed a fall only, starting after at least 4 days and maximal at 20 days $(p<0.001)$. All cause mortality rose on day 1 but then fell, to a minimum also at 20 days (both $\mathrm{p}<0.001$ ).

\section{Discussion}

Both the direct mortality/temperature relations at successive delays and the analysis of filtered data indicate a rapid adverse effect of cold weather on IHD mortality at 15 to $0^{\circ} \mathrm{C}$ and at 0 to $-6.7^{\circ} \mathrm{C}$. The fact that the later rise in RES mortality and the sustained high level of IHD mortality associated with it were reversed below $0^{\circ} \mathrm{C}$ provides a strong indication that the late changes in IHD mortality were linked to RES disease. Respiratory infections are known to be accompanied by IHD mortality. ${ }^{5} 6$ Detailed timings of the different effects must be treated with caution. The rapid adverse effect of cold on IHD deaths in filtered data peaked at 24 hours in the 0 to $-6.7^{\circ} \mathrm{C}$ range. Its apparently later peak at 3 days in the 15 to $0^{\circ} \mathrm{C}$ range is likely to be a result of overlap with the late IHD mortality secondary to RES disease in this temperature range. Similarly, the apparent start of the adverse effect of cold on RES mortality might be delayed by a brief "same day" favourable effect of a cold day on RES mortality. This has been suggested by some studies ${ }^{411}$ but these effects are not demonstrable in the common patterns of cold weather we analysed.

With these reservations about precise timing, likely causes of the effects can be identified. Known thrombogenic and reflex effects of cold exposure provide an obvious cause of the rapid adverse effect of cold that peaked 1 to 3 days after peak cold throughout the 15 to $-6.7^{\circ} \mathrm{C}$ range. Red cell and platelet counts, blood viscosity, plasma fibrinogen, and plasma cholesterol of volunteers increased within an hour of the start of an exposure to cold and reverted within 24 hours after it. ${ }^{2}{ }^{3}$ Thrombi started by this process would cause death as soon as they extended sufficiently to cause fatal obstruction. Some of these thrombi are probably triggered by rupture of atheromatous plaque in a coronary artery ${ }^{17}$ as a result of the increased force of ventricular contraction and possibly by coronary spasm ${ }^{18}$ during the rise in arterial pressure induced by cold. ${ }^{19} 20$ Deaths may also be induced directly by relative myocardial ischaemia resulting from the high arterial pressure and coronary spasm but such deaths seem to be infrequent as they would occur during or just after the cold exposure, before the peak we report. Causes of the delayed effects of cold we observed on RES disease, adverse at 15 to $0^{\circ} \mathrm{C}$ and beneficial at just below $0^{\circ} \mathrm{C}$, are more speculative. These could be caused by increased and reduced respiratory cross infection, as a result of crowding indoors and of bactericidal effects of freezing, respectively. Exacerbation of established RES disease by cold exposure also possibly contributes to the adverse effect of cold, since brief inhalation of warm air is reported to have a lasting beneficial effect on established common colds. $^{21} 22$

The finding that short term temperature reductions in the range 15 to $0^{\circ} \mathrm{C}$ were associated with more excess mortality (IHD (52\%), RES (17\%), and all causes (37\%)) than was indicated by the overall regressions of mortalities on temperature in this range, at optimal delays, was unexpected. The overall regressions represent a combination of long term and short term effects of cold plus the effects of non-thermal seasonal factors such as reduced vitamin $\mathrm{C}$ intake in winter, ${ }^{23}$ which is reported to increase RES but probably not $\mathrm{IHD}^{24}$ mortality. The relatively large short term mortality rates after brief cold, particularly for IHD, suggest therefore not only that any non-thermal adverse effects of winter on mortality are relatively small but that slow seasonal falls in temperature caused less mortality than brief falls. One obvious explanation for this is provided by the reductions in cardiovascular responses to cold that occur when brief exposures to cold are repeated (habituation).$^{25}$ These responses, which shift blood centrally from the cutaneous circulation, lead to the haemoconcentration seen in the cold. ${ }^{26}$ They can be expected to be reduced by repetition during winter.

The general conclusion is that direct exposure to cold and, probably, respiratory cross infections are responsible for most excess winter mortality. Measures to reduce cold exposure therefore provide the clearest means of preventing IHD and probably RES mortality in winter. In the case of RES, immunisation against influenza and treatment of secondary infection can clearly prevent some winter deaths. The practicability of behavioural changes to reduce respiratory cross infection and opportunities for antibiotic treatment of common respiratory viral infections, are limited.

This work was carried out in association with EC Biomed Grant "Eurowinter". We are indebted to RJ Allard for advice on Grant "Eurowinter". We are indebted to RJ Allard for advice on use the of the time-series analysis, to the ONS for permission to use the mortality statistics, the Department of Public Health, St George's Hospital Medical School for providing them, and the Meteorological Office for temperature data.

Funding: HEFCE

Conflicts of interest: none. 
1 Bull GM, Morton J. Seasonal and short-term relationships of temperature with deaths from myocardial and cerebral of temperature with deaths from myoc
infarction. Age Ageing 1975;4:19-31.

2 Keatinge WR, Coleshaw SRK, Cotter F, Mattock M, Murphy $M$, Chelliah $R$. Increases in platelet and red cell counts, blood viscosity, and arterial pressure during mild surface cooling: factors in mortality from coronary and cerebral thrombosis in winter. $B M F$ 1984;289:1405-8.

3 Neild PJ, Syndercombe-Court D, Keatinge WR, Donaldson GC, Mattock M, Caunce $M$. Cold-induced increases in erythrocyte count, plasma cholesterol and plasma fibrinogen of elderly people without a comparable rise in protein C or factor X. Clin Sci 1994;86:43-8.

4 Bull GM. The weather and deaths from pneumonia. Lancet 1980;1:1405-8.

5 Bainton D, Jones GR, Hole D. Influenza and ischaemic heart disease-a possible trigger for acute myocardial infarction? Int 7 Epidemiol 1978;7:231-39.

6 Keatinge WR, Coleshaw SRK, Holmes J. Changes in seasonal mortalities with improvement in home heating in England and Wales from 1964-1984. Int $\mathcal{f}$ Biometeorol 1989;33:71-6.

7 Spodick DH, Flessas AP, Johnson MM. Association of acute respiratory symptoms with onset of acute myocardial infarction: prospective investigation of 150 consecutive patients and matched control patients. Am f Cardiol 1984; 53:481-2.

8 Woodhouse PR, Khaw K-T, Plummer M, Foley A, Meade TW. Seasonal variations of plasma fibrinogen and factor VII activity in the elderly: winter infections and death from cardiovascular disease. Lancet 1994;343:435-9.

9 Biemond BJ, Levi M, Cate HT, van der Pol T, Buller HR, Hack CE, Cate JWT. Plasminogen activator and plasminogen activator inhibitor I release during experimental endotoxaemia in chimpanzes: effect of interventions in the cytokine and coagulation cascades. Clin Sci 1995;88:58694.

10 Eurowinter Group (WR Keatinge, GC Donaldson, et al). Cold exposure and winter mortality from ischaemic heart disease, cerebrovascular disease, respiratory disease, and all causes in warm and cold regions of Europe. Lancet 1997;349:1341-6.

11 Kunst AE, Looman CWN, Mackenbach JP. Outdoor air temperature and mortality in the Netherlands: a time-series

12 Donaldson GC, Keatinge WR. Mortality after cold weather in south-east England. F Physiol 1996;491:56-7P.
13 Mackenbach JP, Looman CWN, Kunst AE. Air pollution, lagged effects of temperature, and mortality: The Netherlands 1979-87. F Epidemiol Commun Health 1993;47:121 26 .

14 Laxminarayan S, Spoelstra AJG, Sipkema P, Westerhof N Transpulmonary pressure and lung volume of cat and newborn-removal of cardiac effects with a digital filter. Med Biol Eng Comput 1978;16:397-407.

15 Hathorn MKS. Respiratory modulation of heart rate in newborn infants. Early Human Development 1989;20:81 99

16 Cochrane D, Orcutt GH. Application of least square regression to relationships containing autocorrelated erro terms. Fournal of the American Statistical Association 1949;44:32-61.

17 Farb A, Tang AL, Burke AP, Sessums L, Liang Y, Virmani R. Sudden coronary death. Circulation 1995;92(7):1701-9.

18 Mudge GH, Grossman W, Mills RM, Lesch M, Braunwald E. Reflex increase in coronary vascular resistance in patients with ischaemic heart disease. New Eng 7 Med 1976;295:1333-7.

19 Collins KJ, Easton JC, Belfield-Smith H, Exton-Smith AN Pluck RA. Effects of age on body temperature and blood Pluck RA. Effects of age on body temperature and blood

20 Woodhouse PR, Khaw K-T, Plummer M. Seasonal variation of blood pressure and its relationship to ambient temperature in an elderly population. $\mathcal{F}$ Hypertens $1993 ; 11: 1267-74$.

21 Ophir D, Elad Y. Effects of steam inhalation on nasa patency and nasal symptoms in patients with the common cold. Am f Otolaryngol 1987;3:149-53.

22 Tyrrell D, Barrow I, Arthur J. Local hyperthermia benefits natural and experimental common colds. $B M \mathcal{F} 1989 ; 298$ : 1280-3.

23 Khaw K-T, Woodhouse P. Interrelation of vitamin C, infection, haemostatic factors, and cardiovascular disease. $B M F$ 1995;310:1559-63.

24 Gale CR, Martyn CN, Winter PD, Cooper C. Vitamin C and risk of death from stroke and coronary heart disease in cohort of elderly people. BMF 1995;310:1563-6.

25 Keatinge WR Survival in cold water. Oxford: Blackwell Scientific Publications, 1969; 59-60.

26 Neild PJ, Syndercombe-Court D, Keatinge WR, Donaldson GC, Mattock M, Caunce M. Role of cold diuresis and natriuresis in the haemo-concentration caused by exposure to cold in man. In: Milton AS, ed. Thermal physiology. Aberdeen: IUPS Thermal Physiology Commission,1993; 95. 